Supplementary Materials

\title{
Synthesis of Dendritic Glycoclusters and Their Applications for Supramolecular Gelation and Catalysis
}

Guijun Wang,* Dan Wang, Jonathan Bietsch, Anji Chen, Pooja Sharma

Department of Chemistry and Biochemistry, Old Dominion University, Norfolk, VA 23529, USA, g1wang@odu.edu

Part IV. Full range of HRMS of compounds 17-18, 20-33 


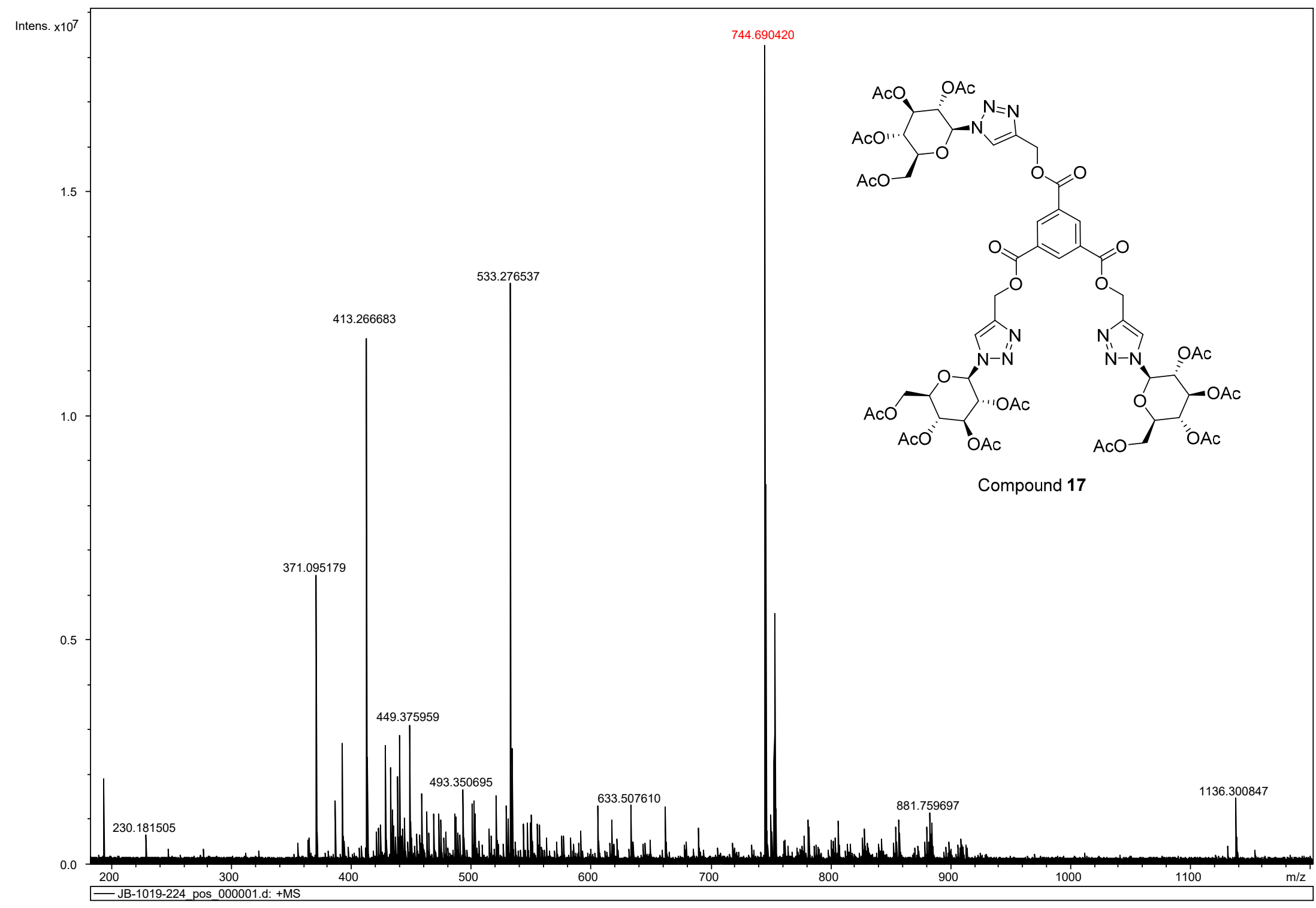




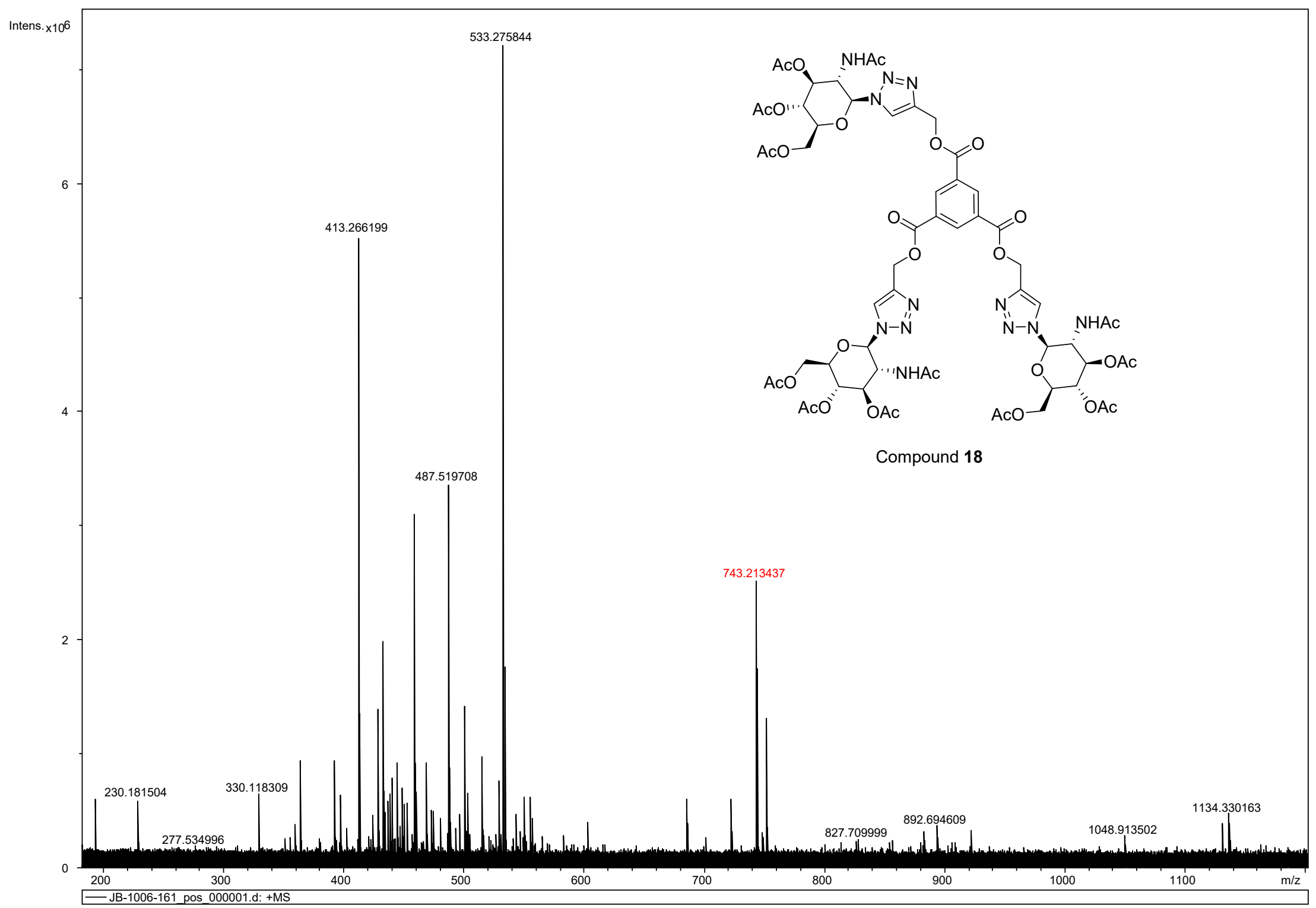




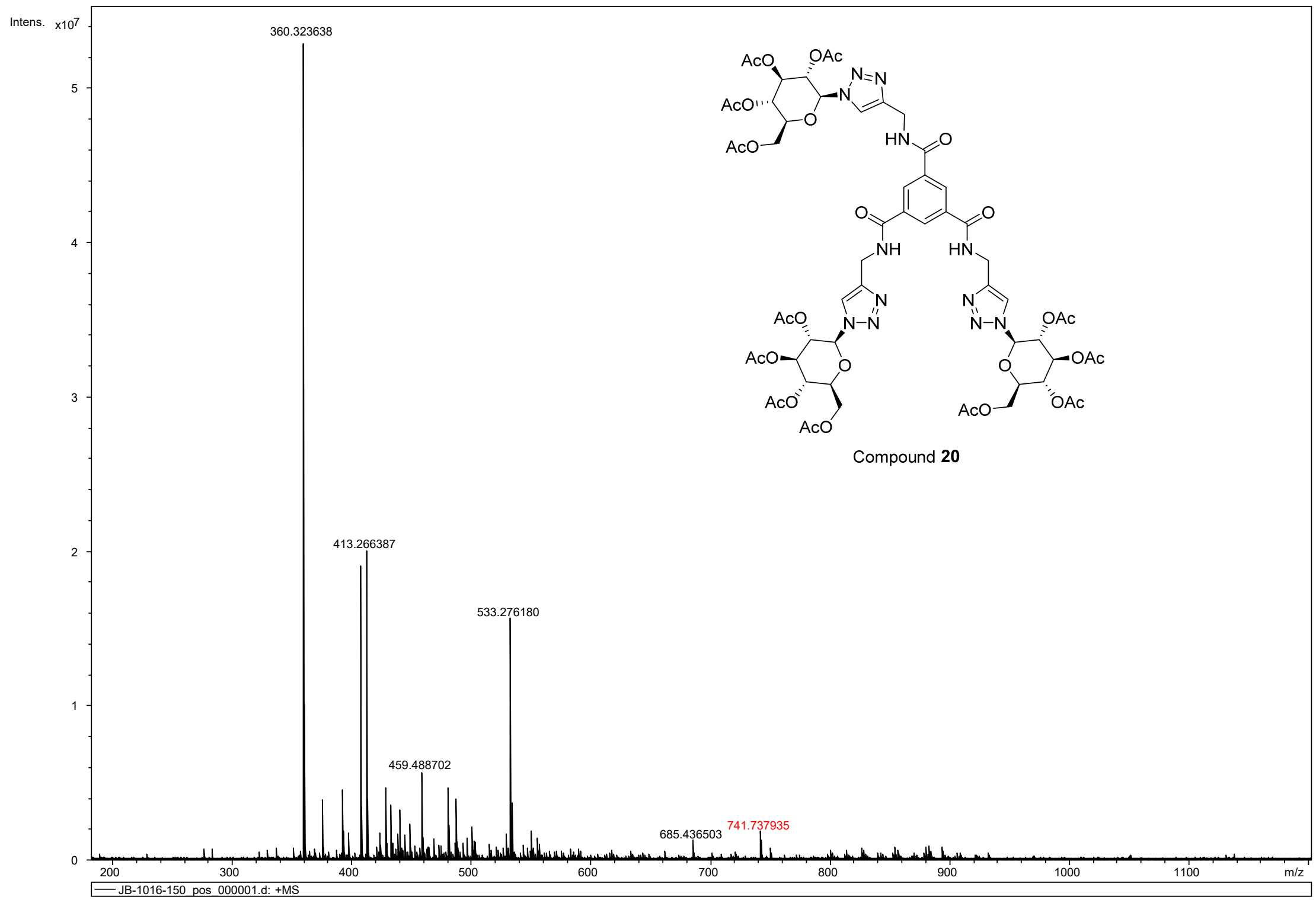




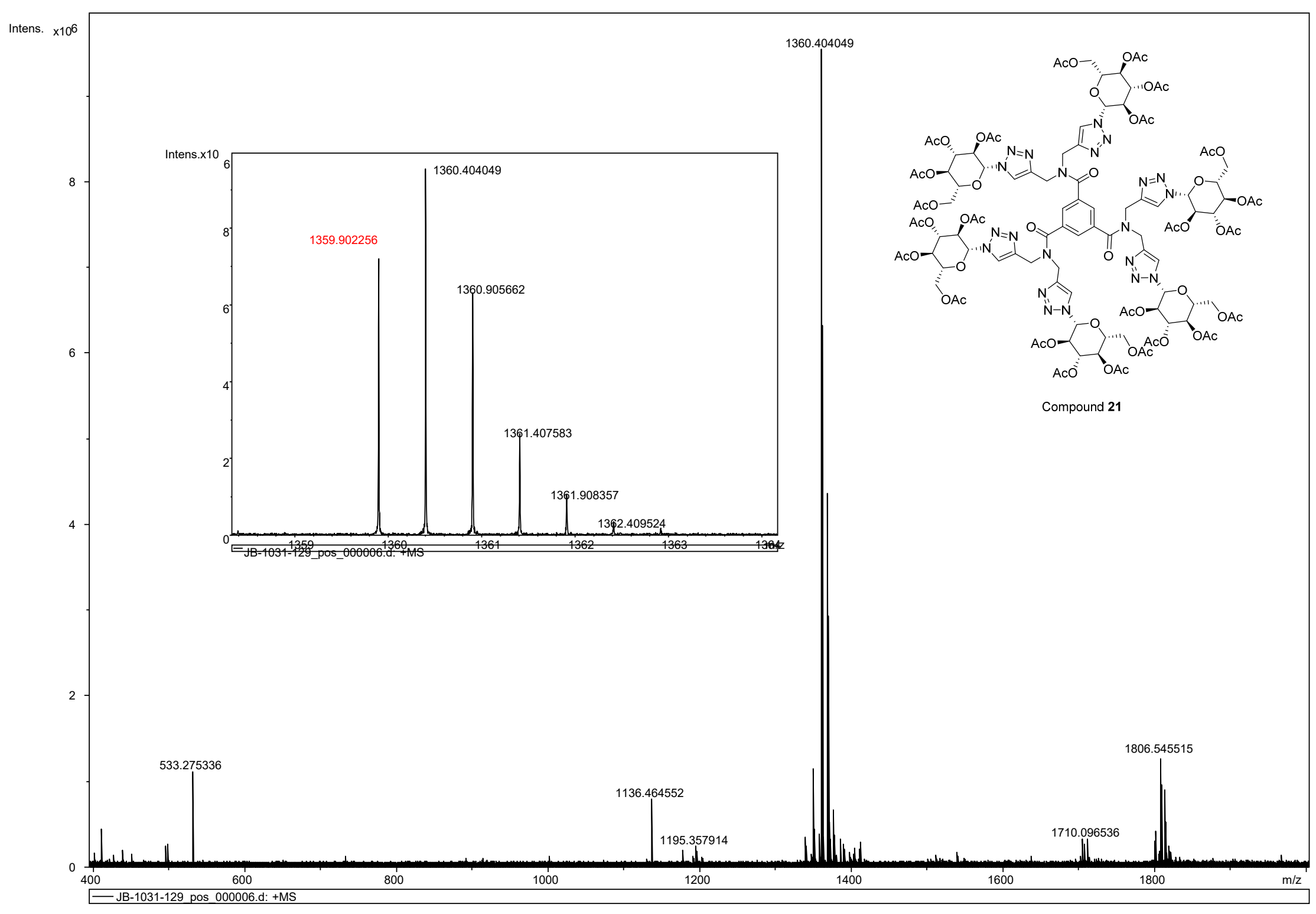




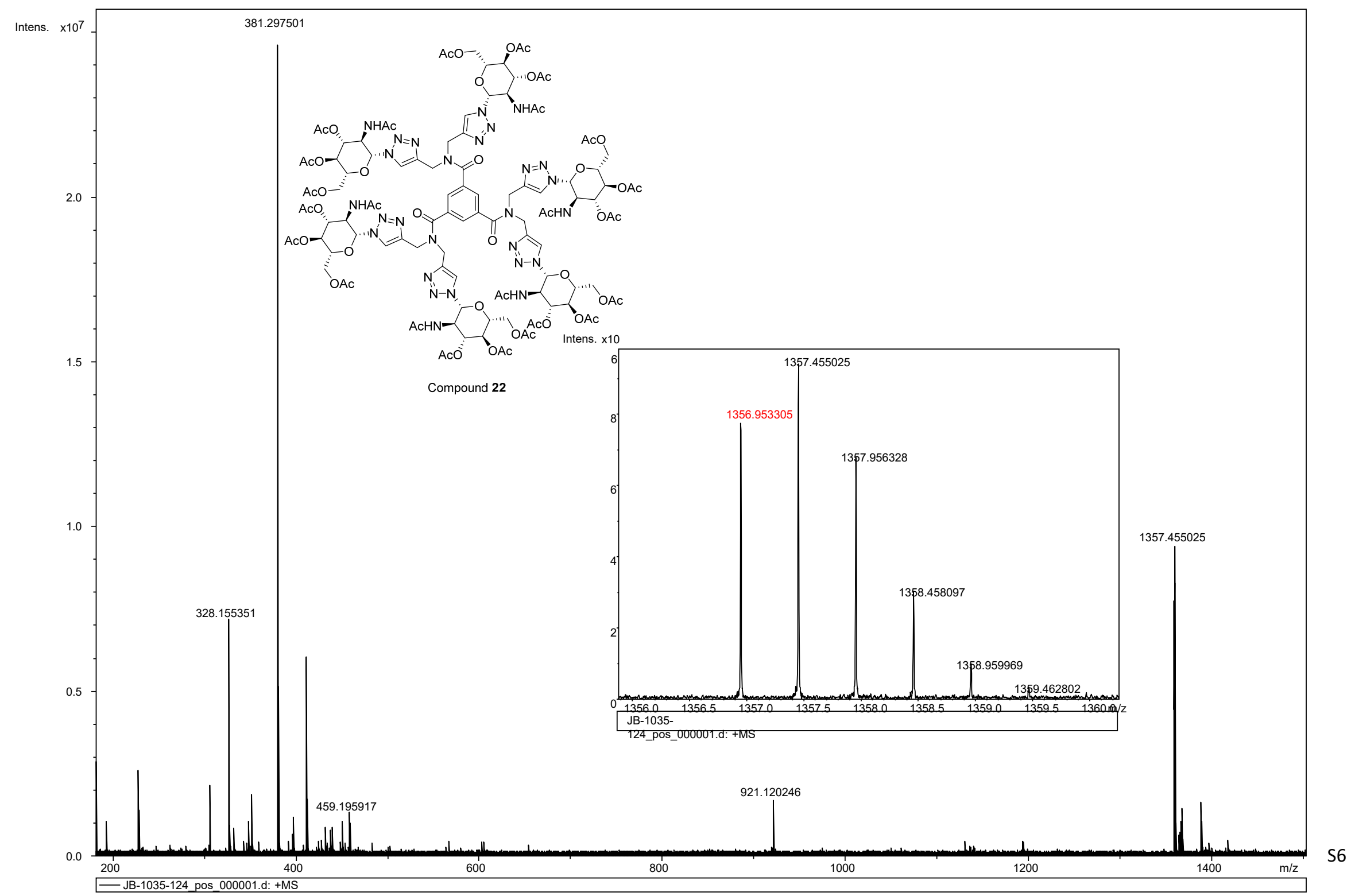




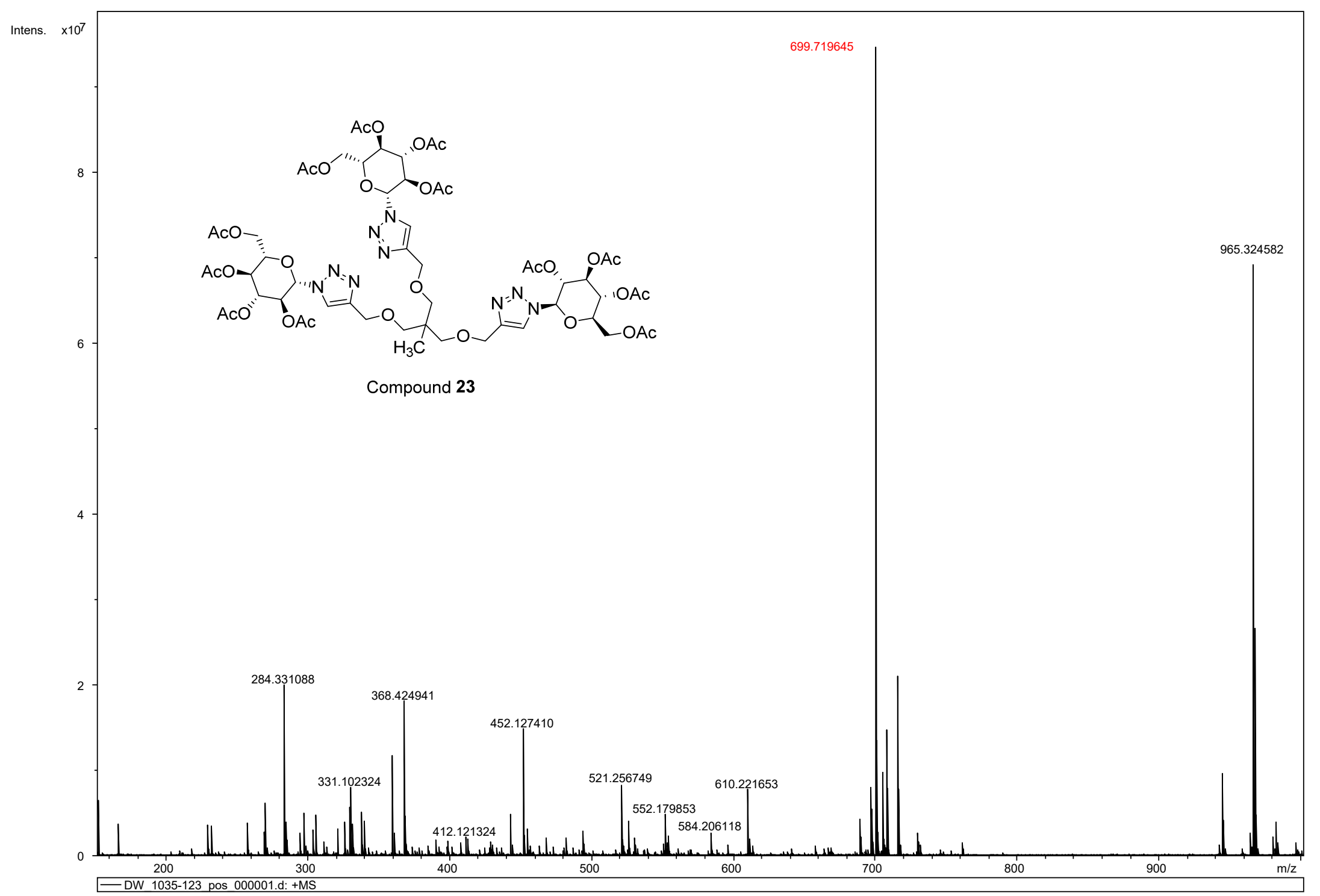




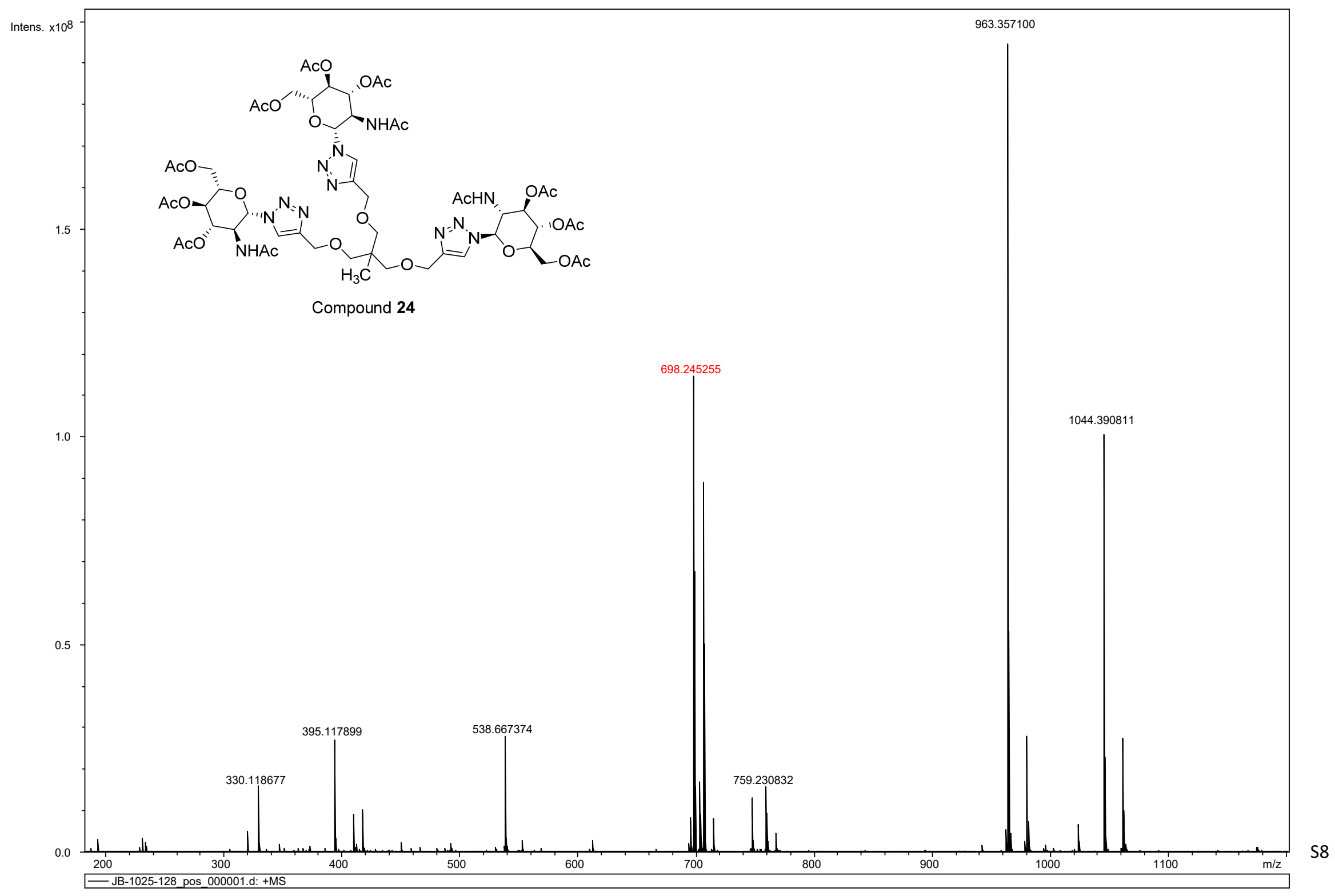




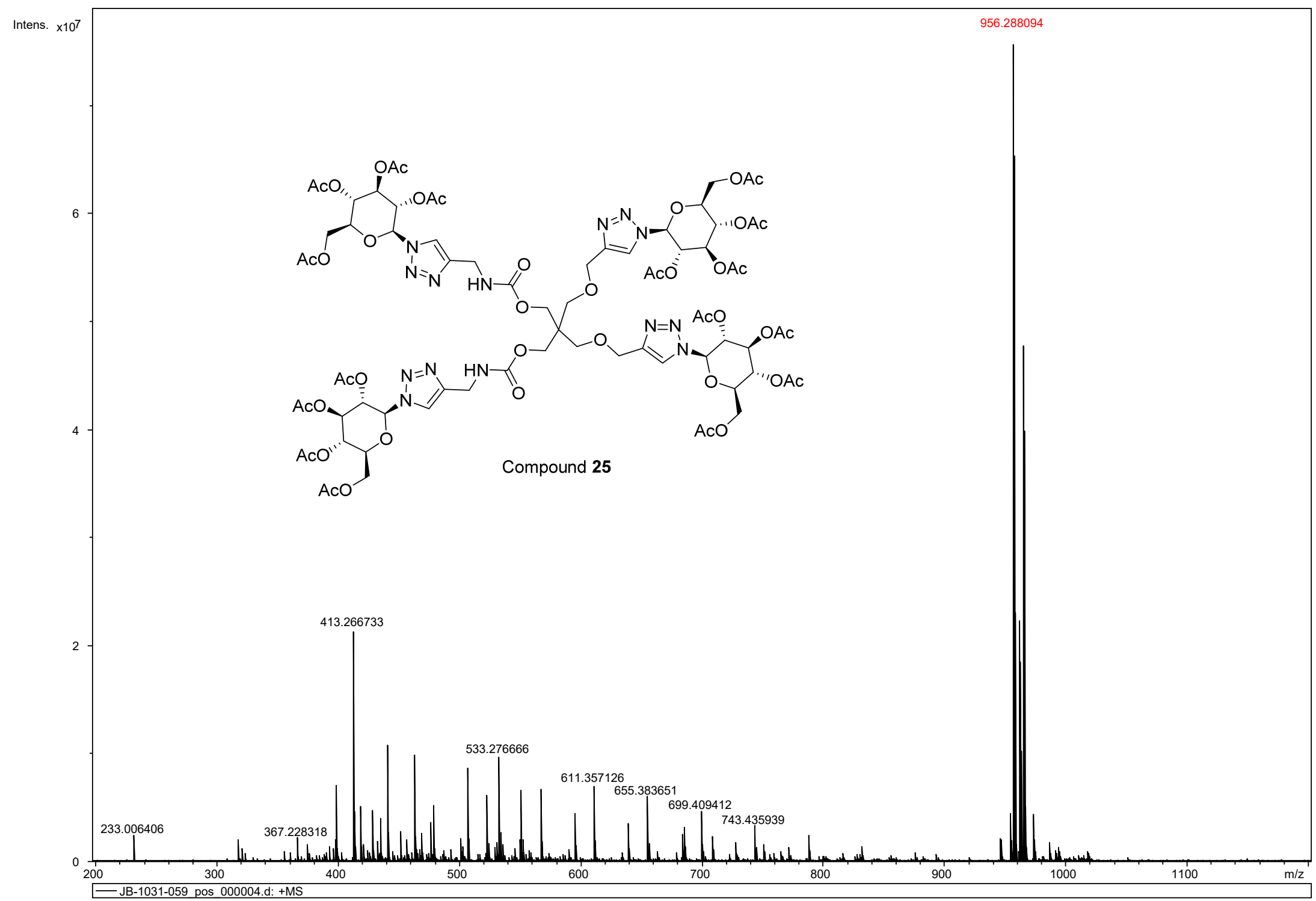




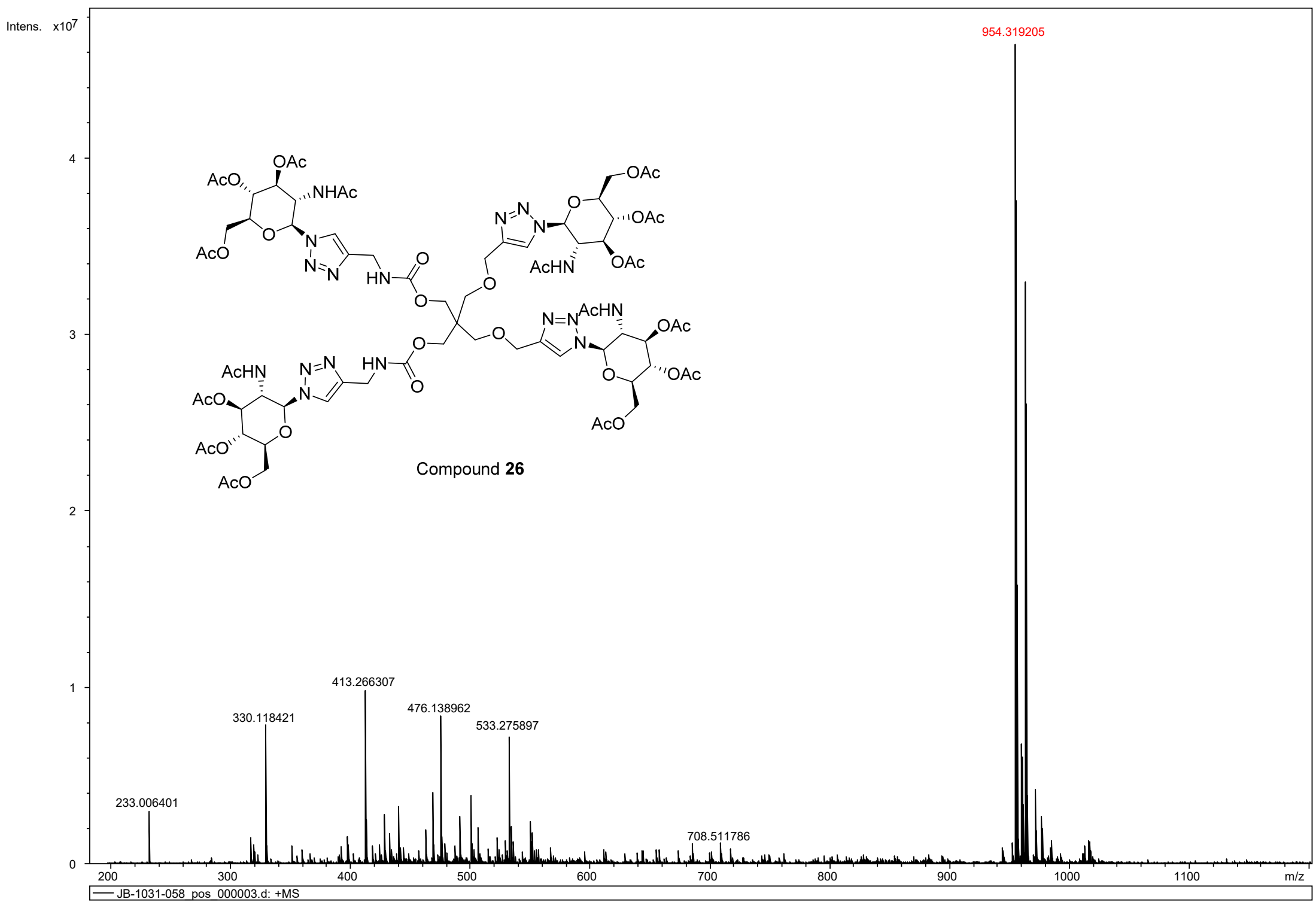




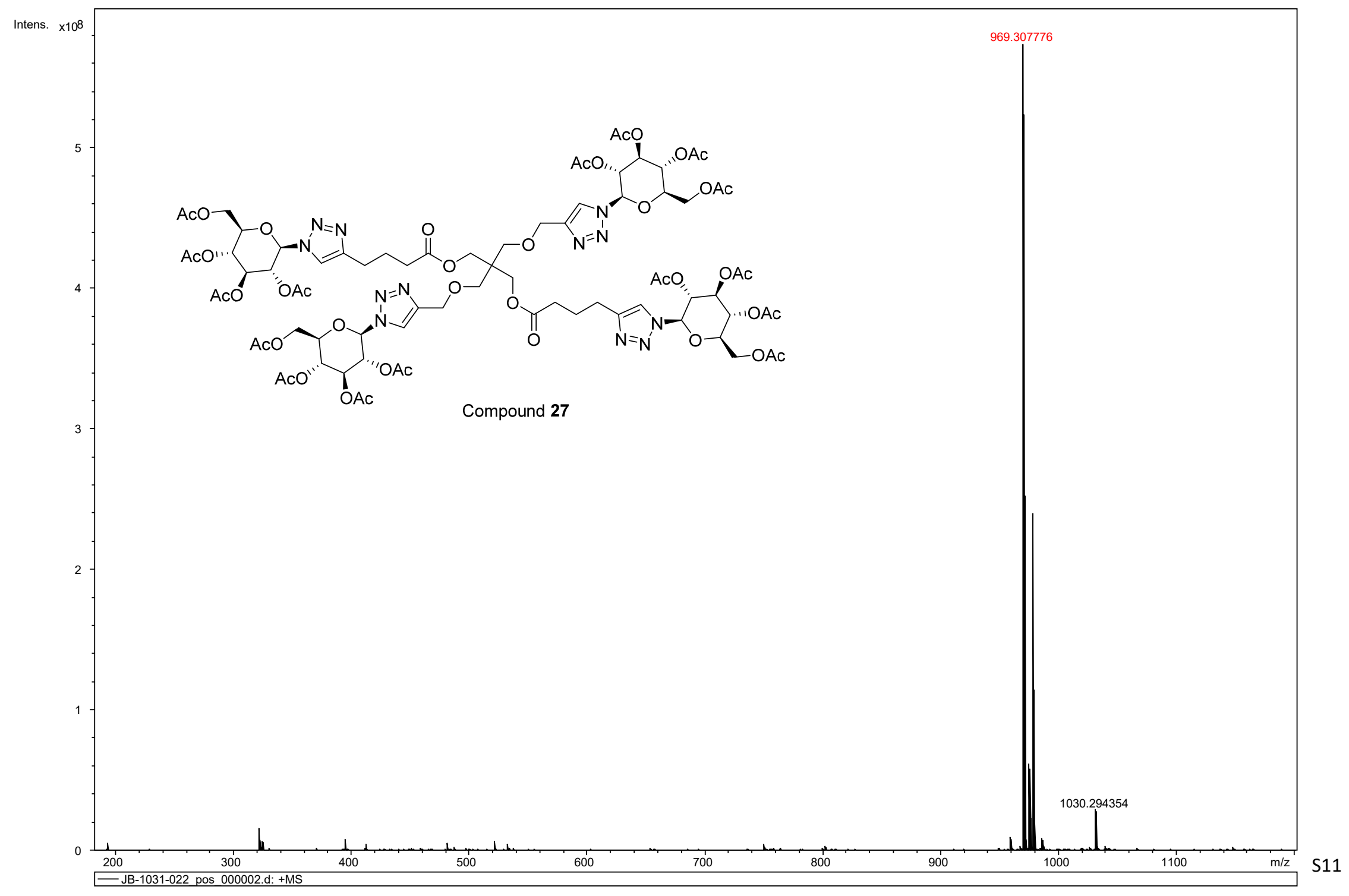




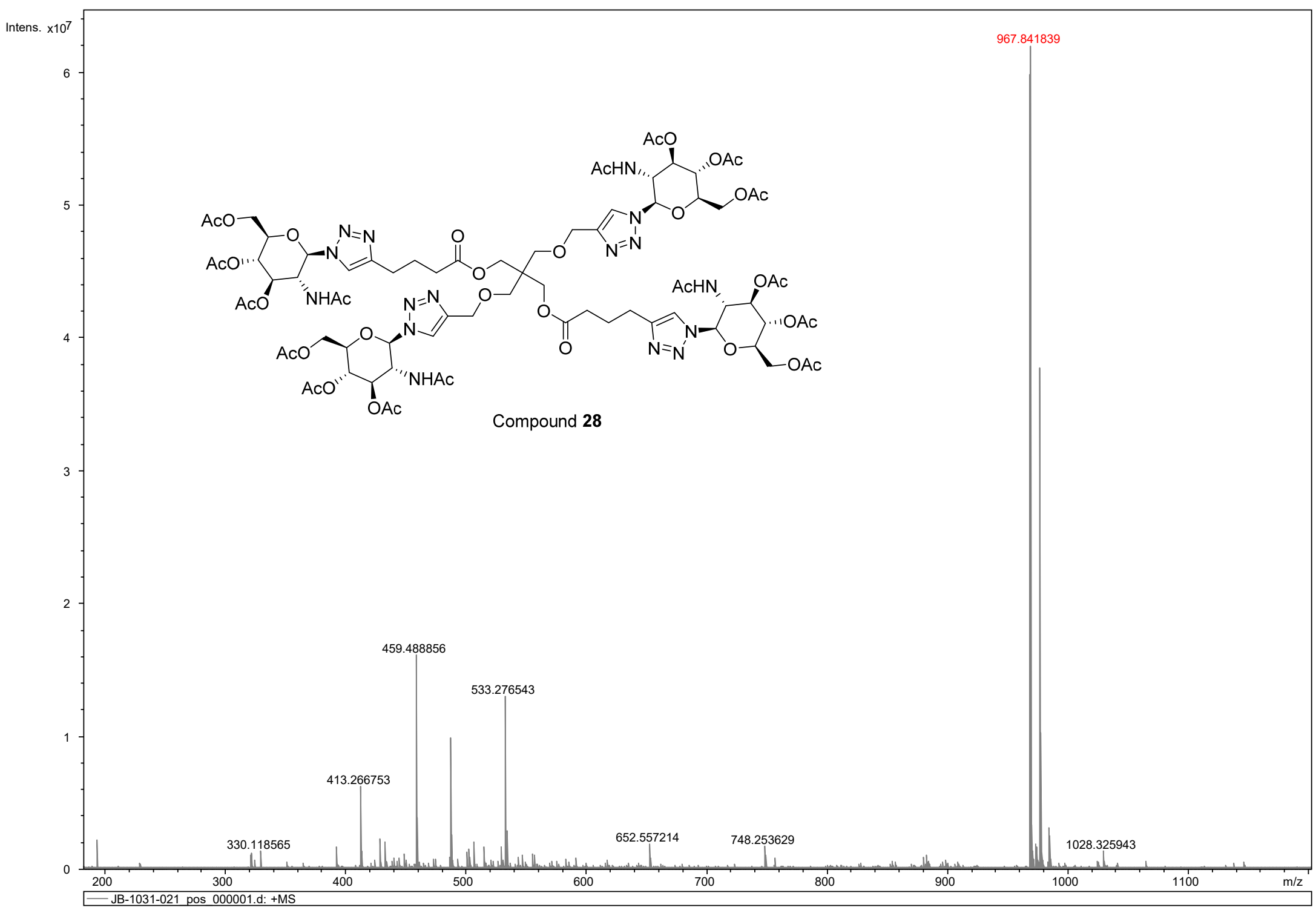




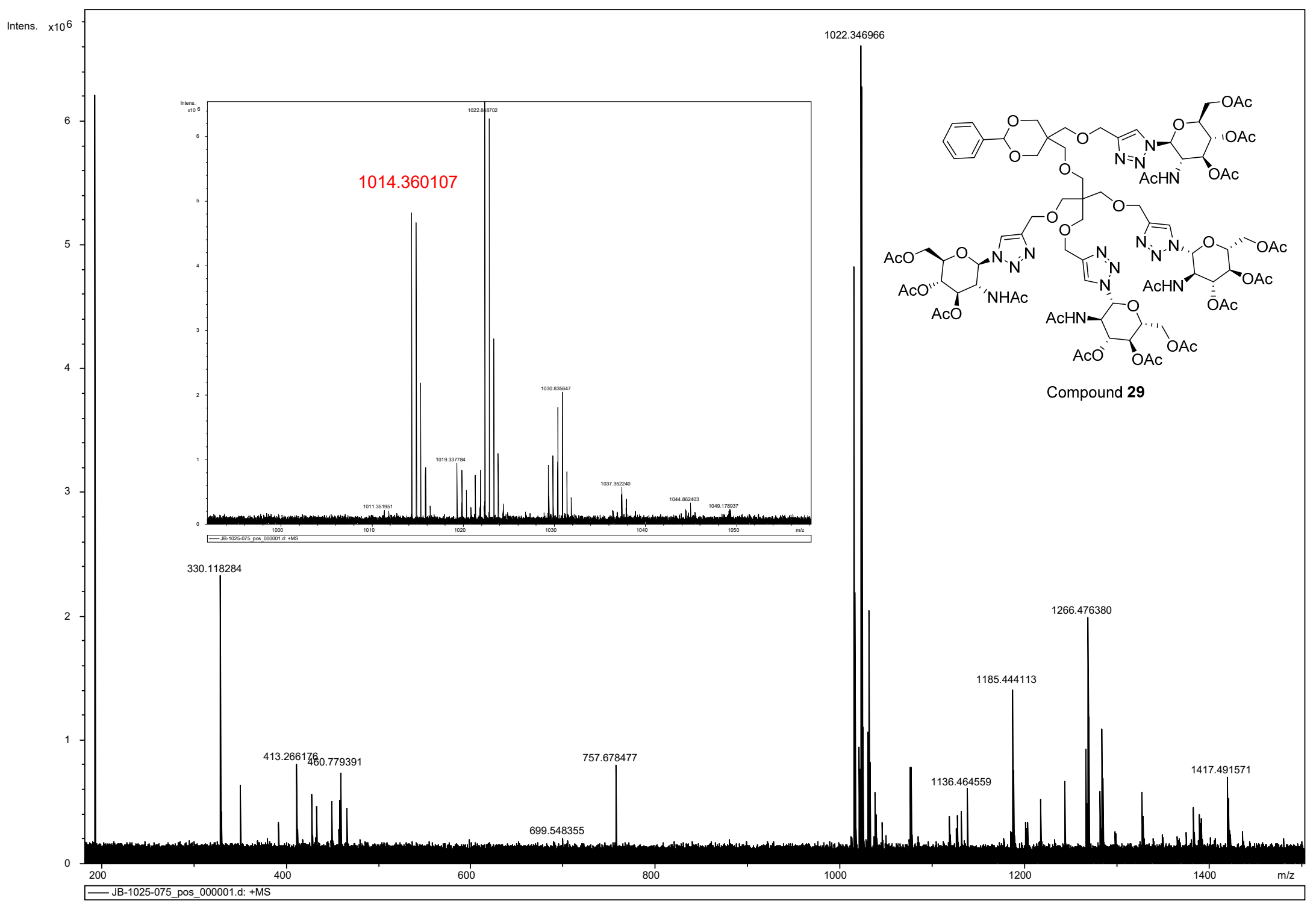




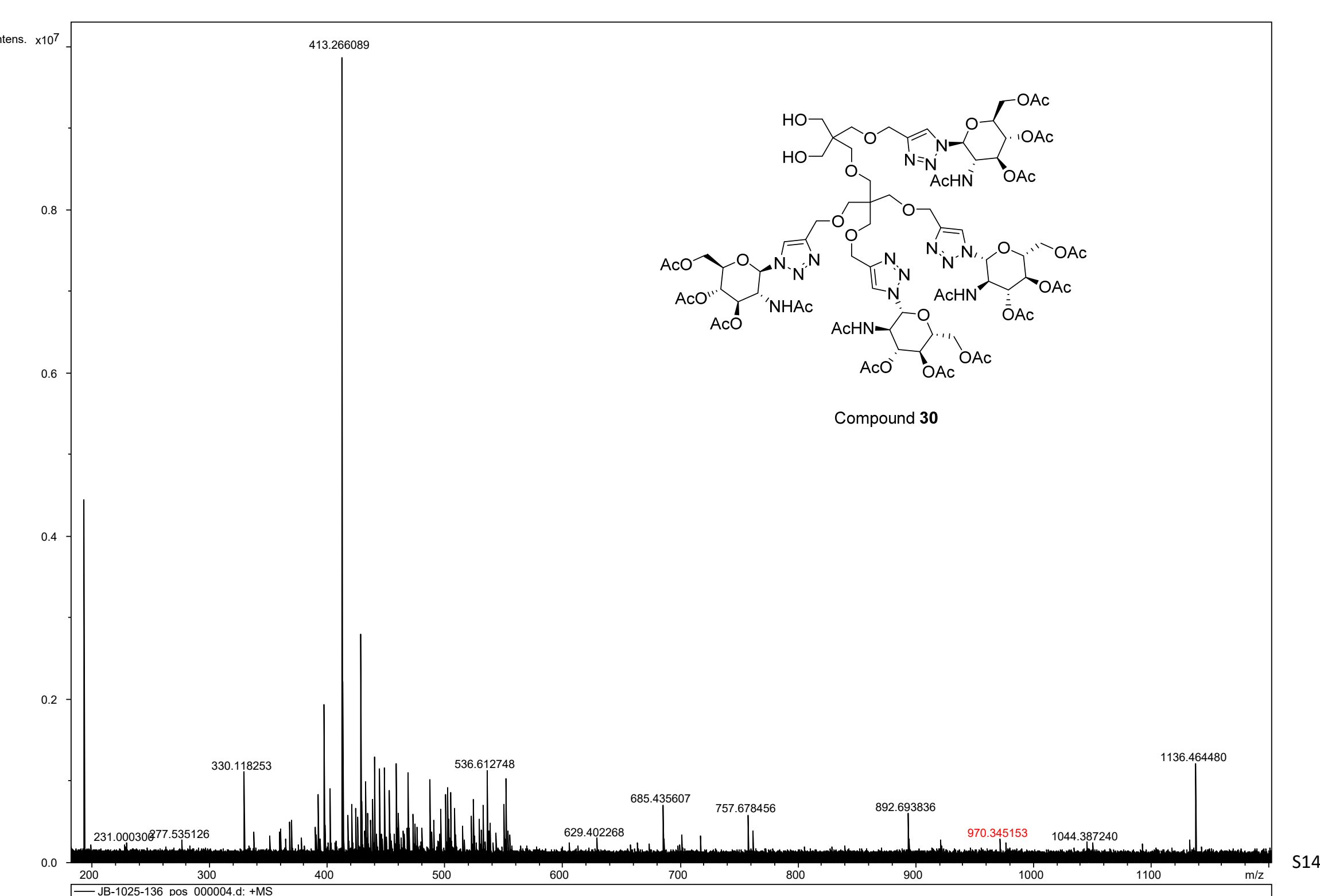




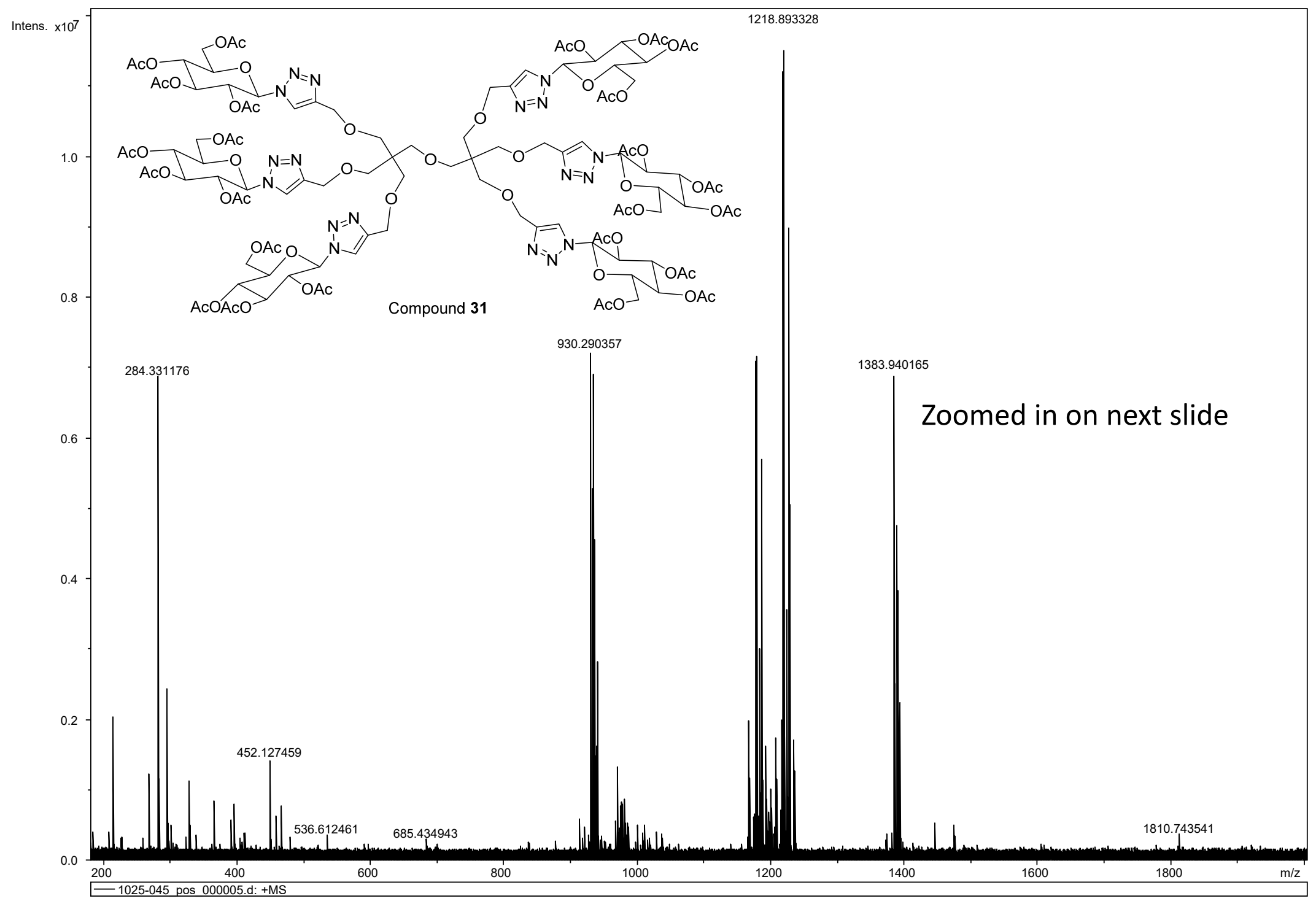




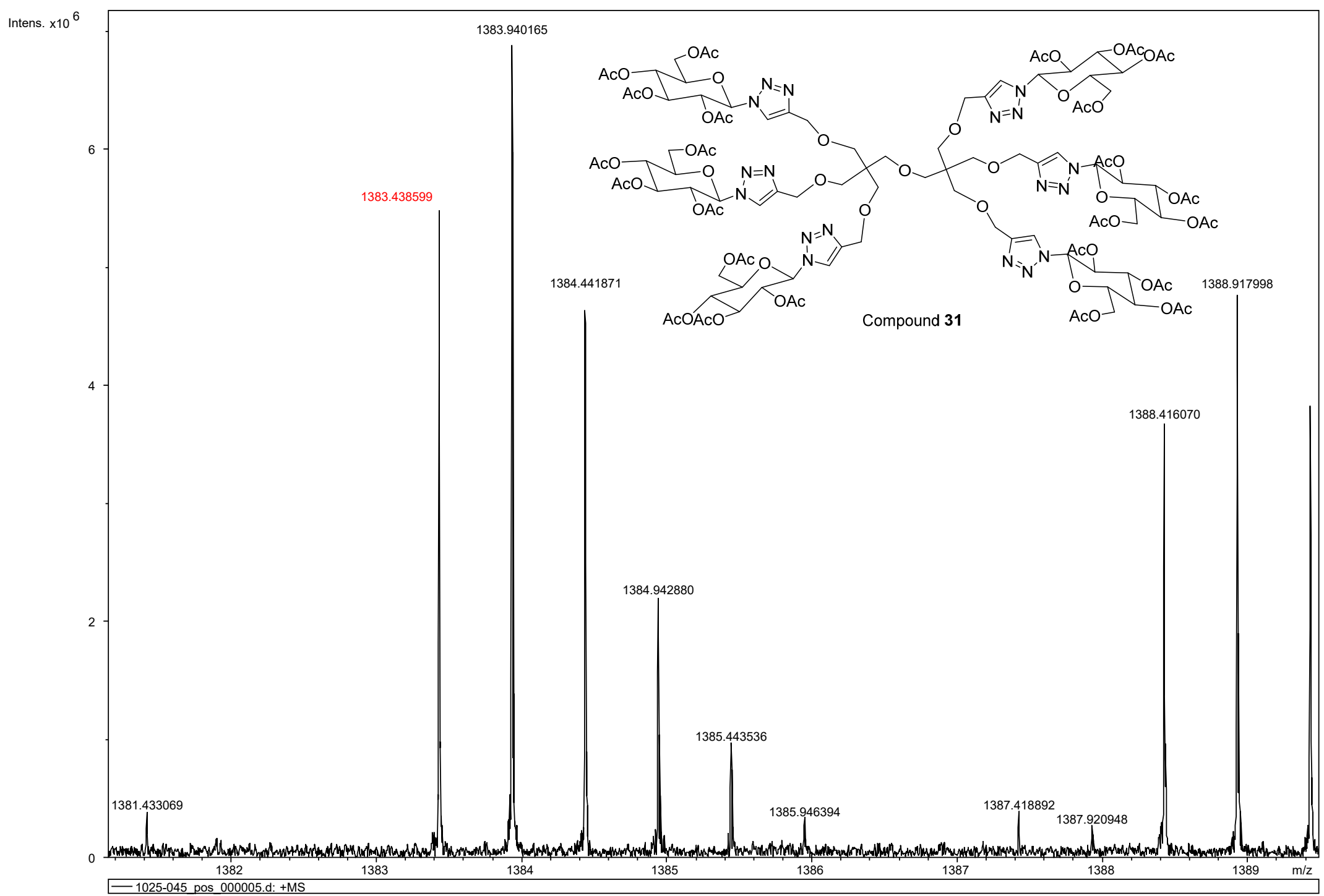




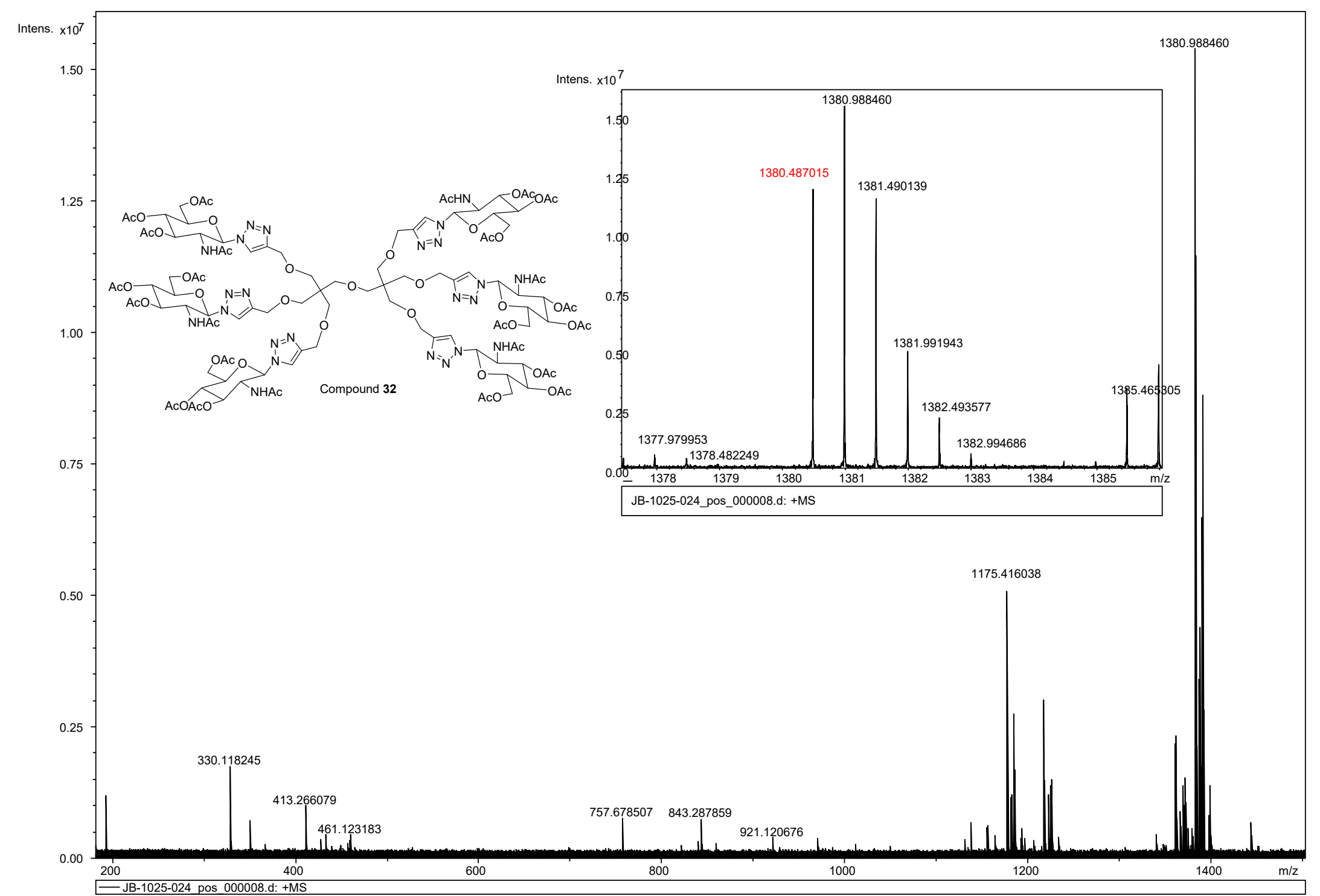




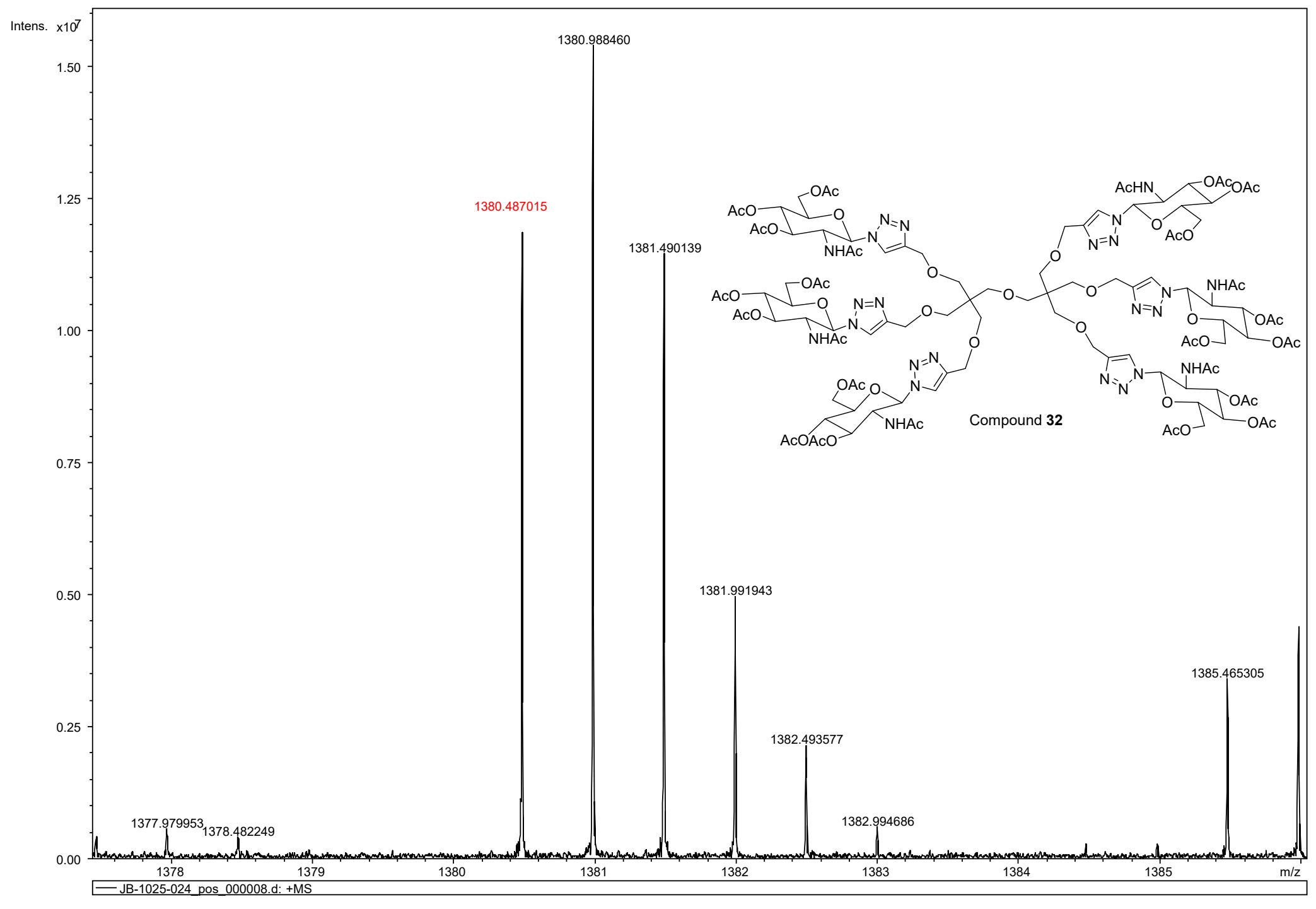




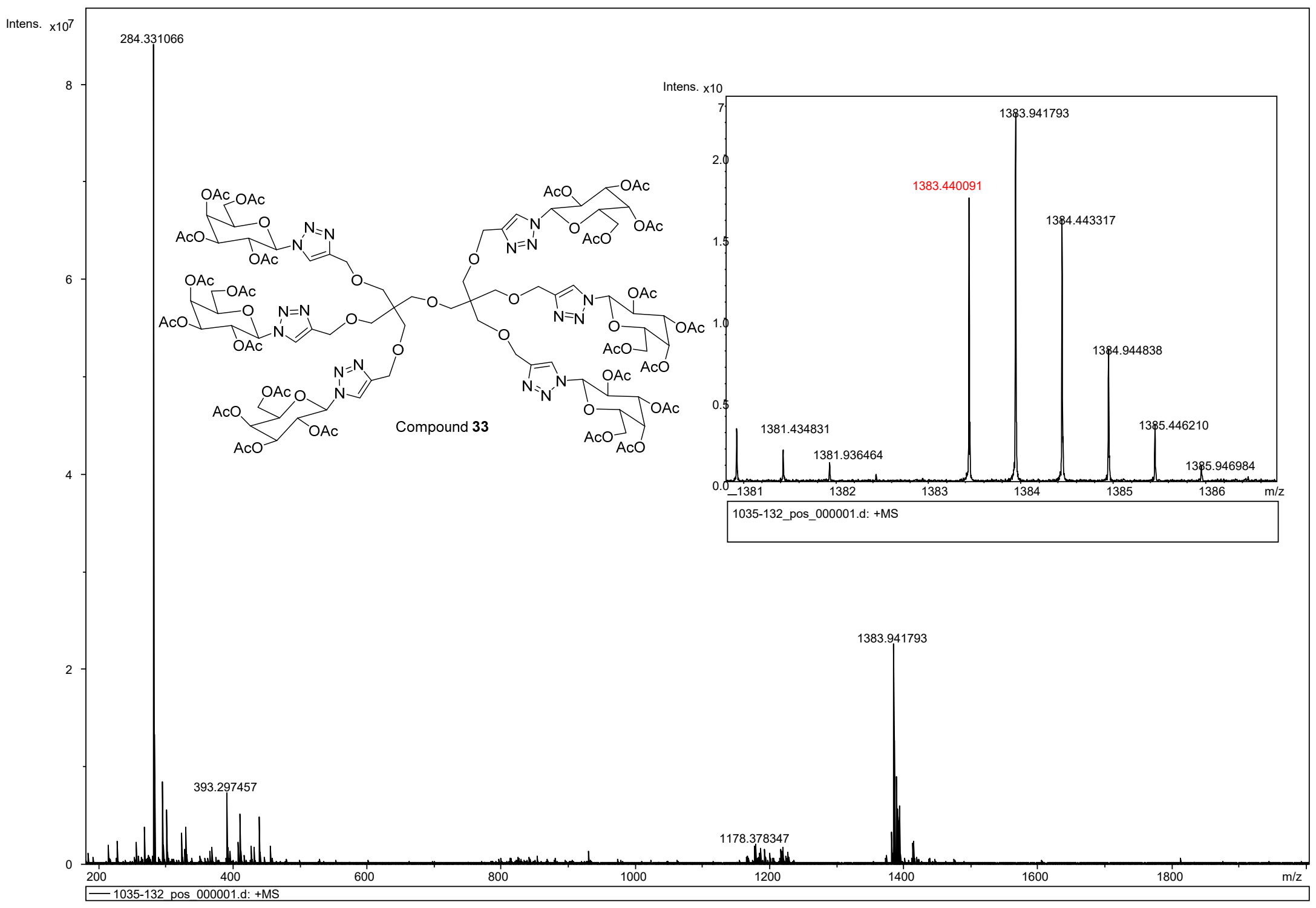

